\title{
JOURNAL OF APPLIED PROBABILITY VOLUME 48 (2011): INDEX
}

Ahn, H.-S. see KIM, J. H.

ANGERER, W. P. New limiting distributions for Bellman-Harris processes . . . . . . . . . . . . .

Arlotto, A., Chen, R. W., Shepp, L. A. And Steele, J. M. Online selection of alternating

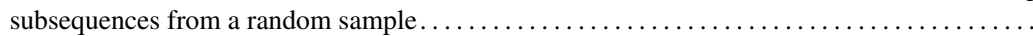

Asselah, A., Ferrari, P. A. and Groisman, P. Quasistationary distributions and Fleming-Viot

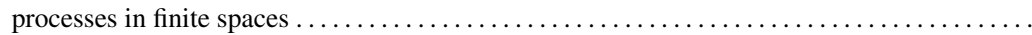

Avrachenkov, K., Piunovskiy, A. And Zhang, Y. Asymptotic fluid optimality and efficiency of

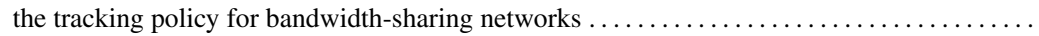

Badescu, A. L., Cheung, E. C. K. and Rabehasaina, L. A two-dimensional risk model with

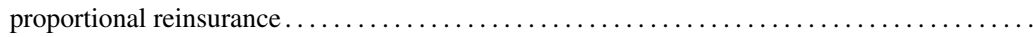

BADIA, F. G. Hazard rate properties of a general counting process stopped at an independent random

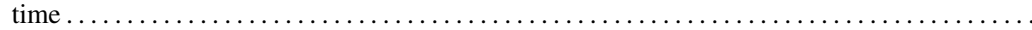

Balakrishnan, N. see Navarro, J. and Xu, M.

Baurdoux, E. J. AND VAN Schaik, K. Further calculations for the McKean stochastic game for a spectrally negative Lévy process: from a point to an interval $\ldots \ldots \ldots \ldots \ldots \ldots \ldots \ldots \ldots$

Berti, P., Crimaldi, I., Pratelli, L. And Rigo, P. A central limit theorem and its applications to

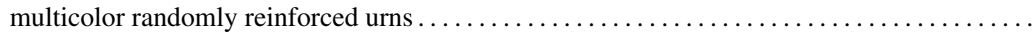

Bertoin, J. On the maximal offspring in a critical branching process with infinite variance.......

Blanchet, J. And Li, C. Efficient simulation for the maximum of infinite horizon discrete-time

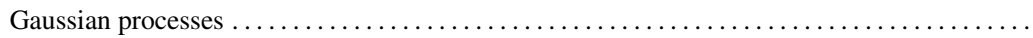

Bo, L., WANG, Y. AND YANG, X. First passage times of (reflected) Ornstein-Uhlenbeck processes

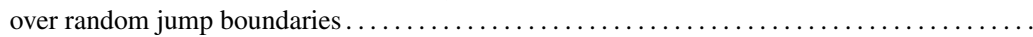

Britton, T., Lindholm, M. AND Turova, T. A dynamic network in a dynamic population: asymptotic properties

CAI, N. Pricing and hedging of quantile options in a flexible jump diffusion model ............

CHA, J. H. AND LEE, E. Y. A stochastic breakdown model for an unreliable Web server system and an optimal admission control policy

—AND FINKELSTEIN, M. On new classes of extreme shock models and some generalizations ...

Chen, A., Feng, L. And Song, R. On the monitoring error of the supremum of a normal jump

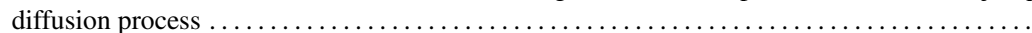

Chen, G. see YAO, C.-L.

Chen, R. W. see Arlotto, A.

Chen, Y. The finite-time ruin probability with dependent insurance and financial risks .........

Cheung, E. C. K. see Badescu, A. L.

Coleman, D. A. see Martin, D. E. K.

Crane, H. A consistent Markov partition process generated from the paintbox process .........

Crimaldi, I. see Berti, P.

Czarna, I. And PAlmowski, Z. Ruin probability with Parisian delay for a spectrally negative Lévy

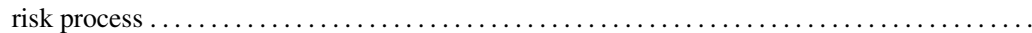

Dassios, A. AND WU, S. Double-barrier Parisian options . . . . . . . . . . . . . . . . . .

De Lima, B. N. B., SANChis, R. And Silva, R. W. C. Percolation of words on $\mathbb{Z}^{d}$ with long-range

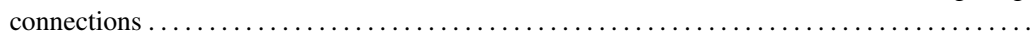

Degen, M. And Embrechts, P. Scaling of high-quantile estimators $\ldots \ldots \ldots \ldots \ldots \ldots \ldots \ldots \ldots$

DeKking, M. And Kong, D. Multimodality of the Markov binomial distribution ...............

$313-321$

$1114-1132$

$322-332$

$90-113$

$749-765$

$56-67$

200-216

527-546

576-582

467-489

$723-732$

1163-1178

637-656

453-466

258-270

$868-876$

1021-1034

1035-1048

778-791

984-1002

1152-1162

968-983

938-953 
DhariYal, I. D. see MisRa, N.

Dong, Y., WAng, G. AND Wu, R. Pricing the zero-coupon bond and its fair premium under a

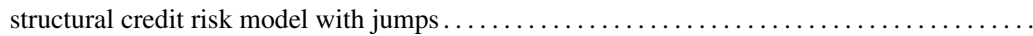

Duffy, K. R., Macci, C. And Torrisi, G. L. Sample path large deviations for order statistics .....

— AND Torrisi, G. L. Sample path large deviations of Poisson shot noise with heavy-tailed

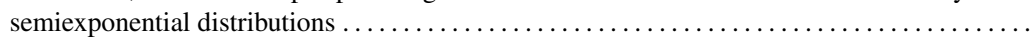

EBRAHIMI, N. AND YANG, Y. An integrated probabilistic model for assessing a nanocomponent's

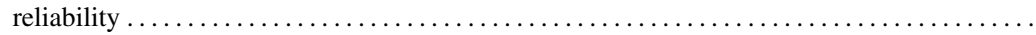

EBRAHIMI, N. Assessing the reliability function of nanocomponents $\ldots \ldots \ldots \ldots \ldots \ldots \ldots \ldots$

EISENBERG, J. AND SCHMIDLI, H. Optimal control of capital injections by reinsurance with a constant

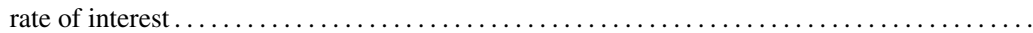

Ejov, V., Litvak, N., Nguyen, G. T. and Taylor, P. G. Proof of the Hamiltonicity-trace conjecture

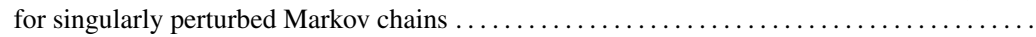

Embrechts, P. see Degen, M.

FAYARD, P. AND FIELD, T. R. Discrete models for scattering populations $\ldots \ldots \ldots \ldots \ldots \ldots \ldots \ldots$

FENG, L. see CHEN, A.

FENG, Q. AND Hu, Z. On the Zagreb index of random recursive trees $\ldots \ldots \ldots \ldots \ldots \ldots \ldots \ldots$

Ferrari, P. A. see Asselah, A.

Field, T. R. see FAYARD, P.

Finkelstein, M. see CHA, J. H.

Franco, T., Neumann, A. And Valle, G. Hydrodynamic limit for a type of exclusion process with

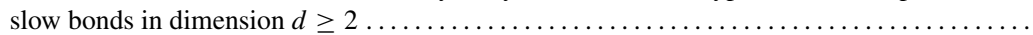

Gasbarra, D., Sottinen, T. and Van Zanten, H. Conditional full support of Gaussian processes

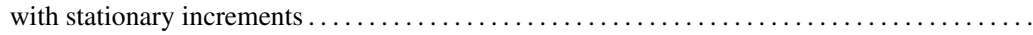

Gerhold, S. The Hartman-Watson distribution revisited: asymptotics for pricing Asian options . .

Gertsbakh, I., Shpungin, Y. and Spizzichino, F. Signatures of coherent systems built with

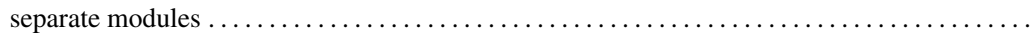

GLYNn, P. W. AND MANDJEs, M. Simulation-based computation of the workload correlation function

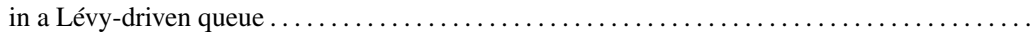

GNEDIN, A. AND IKSANOv, A. Moments of random sums and Robbins' problem of optimal stopping

,-- AND MARYNYCH, A. On $\Lambda$-coalescents with dust component $\ldots \ldots \ldots \ldots \ldots \ldots \ldots$

Groisman, P. see Asselah, A.

Grübel, R. AND WegenER, H. Matchmaking and testing for exponentiality in the $M / G / \infty$ queue .

GuO, T.-D. see YaO, C.-L. and JiAnG, J.

Hartman, J. C. see TAN, C. H.

Hobolth, A. And Jensen, J. L. Summary statistics for endpoint-conditioned continuous-time

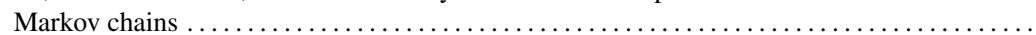

Hu, T. see $\mathrm{Xu}, \mathrm{M}$.

Hu, Z. see FENG, Q.

Ibarrola, R. V. and Prieto-Rumeau, T. Conditionally independent increment point processes . .

ICHIBA, T. AND KaRDARAS, C. Efficient estimation of one-dimensional diffusion first passage time

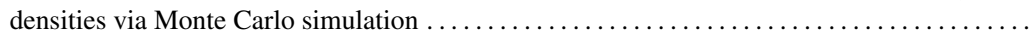

IKsANOV, A. see GNEDIN, A.

JAKUBowsKi, A. AND KarŁowsKA-PIK, J. Processes with block-associated increments ..........

Jensen, J. L. see Hobolth, A.

JIANG, J., ZHANG, S. AND GUO, T. Russo's formula, uniqueness of the infinite cluster, and continuous differentiability of free energy for continuum percolation $\ldots \ldots \ldots \ldots \ldots \ldots \ldots \ldots \ldots \ldots$

Johnson, T. And Waymire, E. C. Tree polymers in the infinite volume limit at critical strong disorder

Junior, V. V., Machado, F. P. And Zuluaga, M. Rumor processes on $\mathbb{N} \ldots \ldots \ldots \ldots \ldots \ldots$

Kalpathy, R., Mahmoud, H. M. and Ward, M. D. Asymptotic properties of a leader election algorithm

404-419

238-257

$688-698$

$832-842$

$31-42$

$733-748$

$901-910$

285-292

$1189-1196$

$333-351$

$561-568$

892-899

$843-855$

114-130

1197-1199

1133-1151

131-144

911-924

$490-513$

699-712

514-526

597-610

885-891

624-636

$569-575$

KARDARAS, C. see IcHIBA, T.

KARŁowsKa-PiK, J. see JAKUBOWsKI, A.

Katayama, T. Some results for vacation systems with sojourn time limits $\ldots \ldots \ldots \ldots \ldots \ldots \ldots$.

Khmaladze, E. V. Convergence properties in certain occupancy problems including the Karlin-

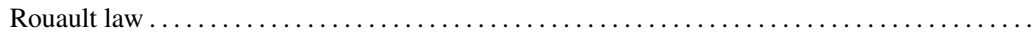

$1095-1113$ 
Kim, J. H., Ahn, H.-S. And Righter, R. Managing queues with heterogeneous servers ......... .

Kochar, S. And Xu, M. On the skewness of order statistics in multiple-outlier models..........

Kong, D. see DeKking, M.

LANCHIER, N. Contact process with destruction of cubes and hyperplanes: forest fires versus tornadoes.

LEE, C. A geometric drift inequality for a reflected fractional Brownian motion process on the positive

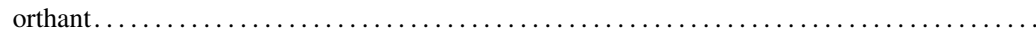

On the return time for a reflected fractional Brownian motion process on the positive orthant

$145-153$

LEE, E. Y. see CHA, J. H.

Li, C. see Blanchet, J.

LindHOLM, M. see BRITTON, T.

LiTVAK, N. see EJOV, V.

LIU, Y. Additive functionals for discrete-time Markov chains with applications to birth-death

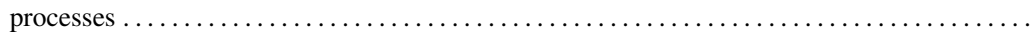

LÖPKer, A. AND Stadje, W. Hitting times and the running maximum of Markovian growth-collapse

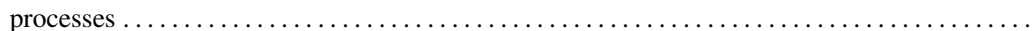

Macci, C. see Duffy, K. R.

Machado, F. P. see JUNiOR, V. V.

Mahmoud, H. M. see Kalpathy, R.

MAndjes, M. see Glynn, P. W.

Marouby, M. Micropulses and different types of Brownian motion

$792-810$

Martin, D. E. K. And Coleman, D. A. Distribution of clump statistics for a collection of words .

MARYNYCH, A. see GNEDIN, A.

Mijatović, A. And Urusov, M. A note on a paper by Wong and Heyde . .

$1049-1059$

Misra, A. K. see MisRa, N.

Misra, N., Misra, A. K. and Dhariyal, I. D. Standby redundancy allocations in series and parallel

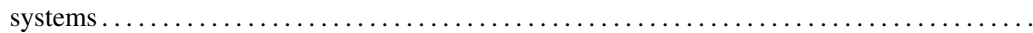

Muhle-Karbe, J. AND Nutz, M. Small-time asymptotics of option prices and first absolute moments

Munsonius, G. O. AND Rüschendorf, L. Limit theorems for depths and distances in weighted

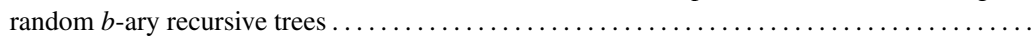

Navarro, J., Samaniego, F. J. and Balakrishnan, N. Signature-based representations for the reliability of systems with heterogeneous components $\ldots \ldots \ldots \ldots \ldots \ldots \ldots \ldots \ldots \ldots \ldots$

Neumann, A. see Franco, T.

Nguyen, G. T. see Ejov, V.

Nishide, K. AND Rogers, L. C. G. Optimal time to exchange two baskets

Nutz, M. see Muhle-Karbe, J.

O’Neill, P. D. see Spencer, S. E. F.

PALMOWSKI, Z. see CzARNA, I.

PINELIS, I. Exact lower bounds on the exponential moments of truncated random variables .......

Piunovskiy, A. see Avrachenkov, K.

Pollak, M. and Tartakovsky, A. G. On the first exit time of a nonnegative Markov process started at a quasistationary distribution

$811-819$

$1060-1080$

$856-867$

Pratelli, L. see Berti, P.

Prieto-Rumeau, T. see Ibarrola, R. V.

Rabehasaina, L. see Badescu, A. L.

Righter, R. Stochastic comparison of discounted rewards see KIM, J. H.

Rigo, P. see BERTI, P.

Rogers, L. C. G. see Nishide, K.

Rüschendorf, L. see Munsonius, G. O.

Samaniego, F. J. see Navarro, J.

SANCHIS, R. see DE LIMA, B. N. B.

SCHLEMm, E. On the Markov transition kernels for first passage percolation on the ladder ........

SCHMidLI, H. see EISENBERG, J.

Shepp, L. A. see Arlotto, A.

Shrungin, Y. see GertsbakH, I. 
Sigman, K. AND Whitt, W. Heavy-traffic limits for nearly deterministic queues.

Silva, R. W. C. see De Lima, B. N. B.

Smythe, R. T. Generalized coupon collection: the superlinear case

SONG, R. see CHEN, A.

SotTinen, T. see Gasbarra, D.

SPEnCER, S. E. F. AND O'NeILl, P. D. The probability of containment for multitype branching

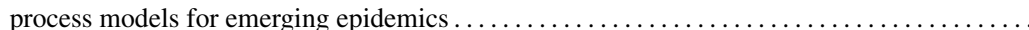

SPizzichino, F. see GerTsbaKh, I.

STADJE, W. see LÖPKER, A.

Steele, J. M. see Arlotto, A.

Tan, C. H. And Hartman, J. C. Sensitivity analysis in Markov decision processes with uncertain

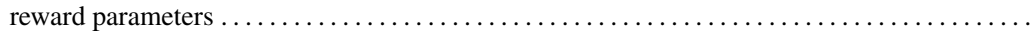

TANG, A. K. see Xu, W.

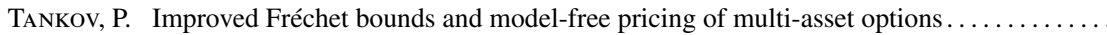

TAqqu, M. S. see Veillette, M. S.

Tartakovsky, A. G. see Pollak, M.

TAYlOR, P. G. see EJOV, V.

Thomas, P. J. A lower bound for the first passage time density of the suprathreshold Ornstein-

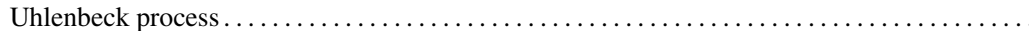

TORrisi, G. L. see DufFy, K. R.

Turova, T. see Britton, T.

Tzioufas, A. On the growth of the one-dimensional reverse immunization contact processes .....

Urusov, M. see MiJatović, A.

Valle, G. see Franco, T.

VAN Schaik, K. see Baurdoux, E. J.

VAn Zanten, H. see Gasbarra, D.

Veillette, M. S. AND TAQQu, M. S. A technique for computing the PDFs and CDFs of nonnegative

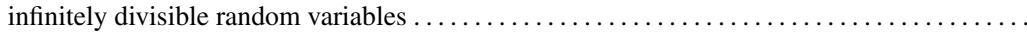

WALTON, N. S. Utility optimization in congested queueing networks $\ldots \ldots \ldots \ldots \ldots \ldots \ldots \ldots$

WANG, G. see Dong, Y.

WANG, Y. see Bo, L.

WARD, M. D. see KALPATHY, R.

WAYMire, E. C. see Johnson, T.

WEgENER, H. see GRÜBEL, R.

Whitt, W. see Sigman, K.

Wong, B. On Wong and Heyde (2004)

Wu, R. see Dong, Y.

Wu, S. see Dassios, A.

XU, M. AND BALAKRISHNAN, N. On the convolution of heterogeneous Bernoulli random variables

- AND Hu, T. Some inequalities of linear combinations of independent random variables. I. ... see KOCHAR, $\mathrm{S}$.

XU, W. AND TANG, A. K. A generalized coupon collector problem

YANG, X. see Bo, L.

YANG, Y. see EBRAHIMI, N.

YANO, K. AND YASUTOMI, K. Realization of an ergodic Markov chain as a random walk subject to

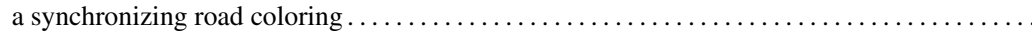

Yao, C.-L., Chen, G. and Guo, T.-D. Large deviations for the graph distance in supercritical continuum percolation

Yasutomi, K. see Yano, K.

YU, Y. Concave renewal functions do not imply DFR interrenewal times....

ZHANG, S. see JiANG, J.

Zhang, Y. see Avrachenkov, K.

ZIPKIN, P. On Durbin's series for the density of first passage times

Zuluaga, M. see Junior, V. V. 